\title{
Aleksandr Bogdanov's Podbor and Proletkult: An Adaptive Systems Perspective
}

\author{
PETER DUDLEY \\ Dudley Consulting, United Kingdom; email: peter@peter-dudley.com \\ Commentary by ORSAN SENALP
}

\begin{abstract}
Keywords: Aleksandr Bogdanov, Proletkult, theatre of the oppressed, social control, adaptive systems
\end{abstract}

If one accepts (following Poustilnik 1995 and 1998) that Aleksandr Bogdanov's intention in using the term podbor over otbor aimed at defining the process by which the 'system in its environment' comes into and continues in existence, one is also constrained to accept that such systems are active agents in the definition of self. Systems that create and maintain themselves in this way actively 'assemble' or construct themselves in reference to the nature of their relationship with their environments, rather than passively surviving in relation to environmental conditions. By extending this interpretation (of the choice of podbor over otbor) to the proletariat, as an individually and collectively adaptive system, it becomes possible to visualize the Proletkult as a conscious project to create an environment where it (the proletariat) could construct and adapt itself as a politically active, relevant and dominant class, thereby placing creative and cultural workers in the forefront of radical social change.

\section{Introduction}

Adaptive systems do not exist in isolation; they are always, and of necessity, embedded in an environment with which they interact. Understood in this way, adaptive systems are identifiable as those that are capable of changing their behaviour and their structure in response to environmental conditions. Such changes can be taken as indicating some internal stress caused by the interaction of the system with its environment, and that the purpose of such systems (to the extent that any given system under consideration can be said to be purposeful) will be to act such as to bring about the reduction or removal of that stress. This is suggestive of the existence of the potential to influence the behaviour of a given system indirectly, by influencing or manipulating its environment rather than attempting to control the system by direct means. This indirect approach is implicit in, for example, Bateson's 'aetiology of schizophrenia' (Bateson 1972), Bowlby's 'Attachment Theory' (Bowlby, 1969-80) and, more recently, the work of Lepskiy in relation to what he calls 'Third Order Cybernetics' (e.g., Lepskiy, 2019), all of which refer to/rely on the use of environmental pressures to affect (for therapeutic/benevolent or pathological/malevolent ends) the behaviour of some or other system-ofinterest. 
Given that this notion of the manipulation of systemic behaviour can also be shown to be a key mechanism in the role of contemporary geopolitics, it is suggested that an understanding of the application of adaptive-systems theory to the manipulation of socio-political attitudes is apposite.

It is suggested that the Proletkult (Proletarian Cultural-Educational Organization), as part of a wider social change movement, can usefully be conceived of as an integral part of an adaptive system, and that Aleksandr Bogdanov, whilst he may or may not have conceived it in this way, had the intellectual models available from Tektology 1913-22 to be able to recognize its utility when viewed as a theoretical and historical necessity to the ongoing viability of the revolutionary movement. Bogdanov was certainly aware of the importance of the impact of culturally defined habits and diversions on the ability of Labour to revitalize itself, for example, where the 'cultural needs of workers acquire [a] pressing character' (Bogdanov 1996: 287), cultural considerations such as'living connexion with nature ... theatres, museums, books ... must come into the calculation' (Bogdanov 1996: 295). From this it can be argued that three particular insights from Tektology, namely, 'bi-regulator', podbor and 'crisis', provide a basis for analyzing the conception of the function of the Proletkult. The Proletkult can be viewed less as a crude anti-bourgeois reaction and more as one which allows the conception of culture (regardless of its detailed content), specifically a consciously designed cultural movement, as a structural and political tool for the delivery and continuation of socio-political change.

Antonio Gramsci's notion of cultural hegemony on the part of the dominant group, class or ideology suggests that any cultural form that seeks to engender socio-political change will of necessity sit on the margins of what is considered to be cultural. A contemporary Marxist consideration of the political aspects of theatrical form, taken from Augusto Boal's analysis in Theatre of the Oppressed (Boal 1979)' of the development of theatrical forms, is examined here as proxy for cultural form. Boal's work provides an insight into how this particular [cultural] form has been used to serve political ends from Aristotle's conception of 'coercive tragedy' to his own 'poetics of the oppressed' - and are rightly to be regarded as indicators of the cultural dominance inherent in cultural forms.

The paper proceeds in four parts:

1. Political aspects of culture: a consideration of the ways in and the extent to which cultural products (in this case theatre) influence society;

2. Elements of tektology: a consideration of those elements of tektology that may have allowed Bogdanov to regard the Proletkult as part of a wider adaptive system;

3. Adaptive systems: a consideration of the principles of adaptive theory and their relevance to social change; and

4. Reflections: a consideration of the challenges that the adaptive approach poses to the idea of culture as a socio-political change agent.

\section{Man Making Society ...}

'[A]ll theatre is necessarily political ... a weapon. A very efficient weapon' (Boal 1979: ix).

These lines from the first pages of Boal's book on political theatre show a clear reflection of the comparison that Stalin drew between ideas and weaponry. ${ }^{2}$ In the wrong hands (or heads), all ideas, especially those that speak of change or that run counter to the established order, are more dangerous than guns.

1 A Brazilian theatre director, Augusto Boal coined the notion of the 'theatre of the oppressed' in the 1950s, and later published a series of analyses based on his practical work.

2 Reflection in more ways than one, as Boal's intention is exactly the reverse of Stalin's. Nevertheless, the recognition of the power of ideas is the same. 
Whether these beliefs are viewed from the standpoint of ideas in general or, in Boal's case, that of the more specific notion of the theatre as a particular mode of the expression of ideas, they share a common recognition that any danger inherent in ideas is in the extent to which they inspire or inform action. To paraphrase Marx: Not just to interpret the world, but to change it. Thus, danger to the dominant faction or class arises both on the part of those that originate ideas and on the part of those that are exposed to and may act on them. And, by extension, if ideas are to be rendered safe, they must be controlled - by controlling the means of the production of ideas, for example through directed advancement or inhibition of idea-producing individuals; or by manipulating or distorting language such that ideas cannot be formed, as in, for example, Orwell's Newspeak; or by controlling the means by which ideas are promulgated, that is, censorship in any of its many forms.

These mechanisms of control are apparent in Boal's analysis of theatrical forms. Beginning in ancient Greece, in order to take control of the Dionysian feast, which traditionally followed the completion of the harvest, Boal (quoting Hauser 1957) has the tragedians in the pay of the state, retained to create a restraining structure around the workers' potentially dangerous revelry.

'The tragedians are in fact state bursars and state purveyors - the state pays them for the plays that are performed, but naturally does not allow pieces to be performed that would run counter to its policies or the interests of the governing classes' (Boal 1979: Introduction).

According to Boal, the Aristotelian theory of tragedy casts it as a form of social control designed to ensure that the workers were brought to a point where they understood their social failings in relation to the state and landowners, and were encouraged, by way of the didactic elements of plays, to self-impose limits on their behaviour. For Boal, 'Aristotle constructs the first, extremely powerful poetic-political system for the intimidation of the spectator' (Boal 1979: Introduction).

In the Aristotelian form of tragedy, the hero, or main protagonist, has a single, fatal, tragic flaw which eventually brings about his or her downfall. According to Boal, it is by recognizing this flaw in themselves and witnessing the hero's downfall that the audience is brought to a point of catharsis partly owing to terror at the sight of the hero's destruction and partly owing to the release of tension caused as order is restored.

In this coercive form of theatre, the spectators 'delegate power to the characters to act and think in their place [and] in so doing ... purge themselves of their tragic flaw ... of something capable of changing society' (Boal 1979: 155).

Here, Boal is defining a particular cultural product as a method by which to enforce social change. And, although he is defining that power as conservative, as serving the interest of the status quo, it is behavioural change nevertheless. It forces a change in the internal or authentic standards by which behaviour is judged - from standards that may be in the best interest of the self to those that are in the best interests of the dominant group.

From here, Boal moves forward through mediaeval theatre on which he comments that, in so far as the point of Aristotelian tragedy 'was its cathartic function, its function as a purifier of the citizen [and,] in this sense, the medieval theatre was Aristotelian' (Boal 1979: 56).

And on to bourgeois theatre, which, '[w]hile its principal opposition was to the feudal nobility[,] ... directed its energies towards the exaltation of individual man - that same man who was later submitted to severe reduction, by that same bourgeoisie, when its principal opponent came to be the proletariat' (Boal 1979: 65).

Until this point in his analysis, Boal seems to be asserting that theatre has been controlled by and served the purposes of the dominant group in any given society. Whether this group be the aristocracy of ancient Greece, the Church, the feudal aristocracy or the bourgeoisie, the role of theatre seems to have been twofold: it served the purpose of both the lens, through which the individual viewed society, and the mirror, through which he or she saw themselves reflected as a member of that society. It functioned as a mechanism by which individuals could self-correct any failings on their 
part, and thus become more appropriate members of that society. Thus, following Boal, conventional theatre situated both temporally and societally will always function as a lens whereby the audience can be in no doubt as to both the acceptable and the unacceptable values of that society; as a mirror whereby the audience can see themselves and their behaviours reflected in relation to the values of that society; and as a mechanism by which the audience can (vicariously through their empathy with the protagonists) purge themselves of any failings in relation to the values of that society. In this way, theatre can be viewed as a conservative enculturation device.

Yet Brechtian theatre is where Boal begins his consideration of what radical theatre may look like: 'Brecht's poetics is that of the enlightened vanguard: the world is revealed as subject to change ... the spectator does not delegate power to the characters to think in his place, although he continues to delegate power ... to act ...' (Boal 1979: 155).

Here, Boal describes an inversion of previous forms of theatre and the ideas of society to which they were appropriate. Where conventional, or conservative, theatre was deemed to assume that the audience or the individual members of society were malleable, Boal's analysis of Brecht moves this malleability to society. No longer is the corrective direction from the dominant group in society to its disempowered members; society itself has become the object of change. But however much it is possible for a disempowered group to imagine a different future, they are not empowered to create it for themselves. Brechtian theatre retains to itself the right to action; it is 'a preparation for action' (Boal 1979: 155), but it does not provide the disempowered with the means to act themselves.

Boal completes his review of theatrical forms with his own 'theatre of the oppressed', which he describes as 'the poetics of liberation: the spectator no longer delegates power to the characters either to think or to act in his place. The spectator frees himself; he thinks and acts for himself! Theatre is action!' (Boal 1979: 155).

In the 'theatre of the oppressed', the spectators become the actors. They become an integral part of the production able both to question the motivations of the characters presented and to change the course of the action, and, in this way, are empowered to define the production in such a manner that it reflects their experience and their desires. As Boal says, 'the theatre is not revolutionary in itself; but have no doubts, it is a rehearsal of revolution!' (Boal 1979: 155).

Boal, in presenting his analysis of theatrical forms in relation to the social structures they support, also, by definition, provides an analysis of social forms that can be represented as set out in the diagram below. And, by considering mechanisms by which this can be achieved, that is, that coercive theatre is suited to a monothetic acquisitive society and that what he describes as liberating theatre is suited to a more distributive society and, what is more, the extent to which this liberating theatre can be used to instigate the change from one form to the other, he demonstrates that cultural forms and cultural products can be used to bring about or, at least, prepare for social change.

\begin{tabular}{c|c|c|c} 
Locus & Monothetic & Antithetic & \\
\hline External & $\begin{array}{c}\text { Divine right or } \\
\text { natural order }\end{array}$ & $\begin{array}{c}\text { Intellectualist } \\
\text { socialism }\end{array}$ & $\begin{array}{c}\text { Didactic } \\
\text { utopianism }\end{array}$ \\
\hline Internal & Acquisition & Labour & Synthesis
\end{tabular}

From this demonstration, it seems reasonable to assert that culture or cultural products mediate the interaction of the individual with society, whether this be coercive tragedy in the Aristotelian sense, which presumes the malleability of the mass citizenry and uses intimidatory drama in order to force them to align their desires with those of the dominant faction, or Boal's liberational drama, which 
assumes the malleability of society and uses dramatic technique in order to politicize the citizenry in order that they are able to change it. The existence of both cases alongside each other suggests that both individual and society can be considered malleable and that the form each takes is the result of a dynamic interplay each with the other with this interplay mediated by whichever cultural form is dominant.

\section{Elements of Tektology}

It is clear that Bogdanov recognized the role of culture and cultural products as, at the very least, a form of the replenishment of labour power (see above). The argument that will be proposed in this section is that, whether or not Bogdanov understood the role of culture as part of an interactive system - composed of the individual and society - and, therefore, as a tool for the advancement and maintenance of the revolution, he certainly had conceptual models available (from Tektology) that would allow him to construct it as part of an adaptive system and, therefore, conceptualize the necessity of the Proletkult as an overtly political tool.

Podbor is generally translated in Tektology (even the 1996 edition of Book I) as 'selection' in the Darwinian sense. However Poustilnik has asserted that this rendering de-natures the term which is more akin to 'assemblage' or, perhaps, (self-)construction when used by Bogdanov (Poustilnik 1995). This interpretation suggests a reading of his 'complexes', especially complexes that are subject to what Bogdanov calls 'progressive podbor' (Bogdanov 1996: 190 ff.), as dynamic, and subject to change in relation to their interactions with their environments. What is more, this change is cumulative - such that, although each change in isolation could be considered equilibrating, that is, tending towards a more (local and immediate) equilibrial state, over time the accumulation of such changes could lead to fundamental changes in the nature of the complex. For Bogdanov, under the conditions of progressive podbor, 'the structure of a complex ... [is] what is changing ... [pointing to] the growing complexity and in-homogeneity of the inner correlations' (Bogdanov 1996: 196-197) or, in conditions of adversity, its reverse.

For Bogdanov, podbor was to be understood as more than simply passive growth in the size of a complex; it was the potential for structural change. And this structural change was not a direct function of changes in its environment but a function of changes in the environment as mediated by the relationships between the internal components of the complex and between the complex as a whole and its environment.

That is, under conditions of progressive podbor - whether positive or negative - the cumulative complexification (or simplification) caused by the interaction of the complexes with their environment eventually drives them to a point where their current structure is no longer able to maintain integrity and they are forced to adopt a new and more appropriate structural form. They reach a point of crisis, where 'they cease to be what they were ... and form some new system' (Bogdanov 1996: 157).

The last element of tektology relevant to this section is the 'bi-regulator'which Bogdanov describes as a 'combination in which two complexes mutually regulate each other' (Bogdanov 1989, Book 2: 97). That is, in the context of the above, each stands as the (sufficiently dominant element of the) environment of the other.

When two complexes, each subject to the processes of progressive podbor, and therefore the potential for structural crises consequent thereon, are brought into a relationship of bi-regulation, the nature of the relationship will be such that, however else and however much they are impacted by their wider environments, each will act to modify or constrain the behaviour of the other to the extent that their relationship is maintained. 
A traditional interpretation of this would be that, in effect, internal crises (in either of the participants) are prevented, or that such crises as occur leave the participant in which they occur better adapted to the needs of the other. That is, either the complex as a whole achieves a state of ongoing stability or, following an internal crisis, the participant subject to structural change takes on a form in which it can (perhaps minimally) survive whilst reducing the internal stress this places on its counterpart. Where neither of these outcomes is the case, there is either a complete disruption of the bi-regulative arrangement (the pair separate) or, where the arrangement continues, a radical redefinition of the relationship between them.

It is relatively straightforward to see from this that, in the second case, where the two participants of the bi-regulator cannot completely separate, the radical redefinition of their relationship can be seen to be (an outcome of) revolution. And, following revolution, in circumstances where new trajectories have become possible, the former case is relevant. That is, it is possible for the two participants to co-determine each other's future by acting in such a way as to maintain some form of dynamic internal balance between them. And to the extent that the Proletkult was intended to provide a'distinctly proletarian culture which must arise and replace the doomed culture of the bourgeoisie ... [and the extent that it was held that] Art organizes social experience by means of living images, not only in the sphere of cognition, but also in that of feeling and desires. As a consequence it is a most powerful weapon for the organization of collective forces, and in a class society, of class forces'(SovLit).

It can reasonably be asserted that the original founders of the Proletkult movement considered it to function in much the same way as Boal considered his theatre: if not as revolution in itself then, at the very least, as a permanent preparation for, or perpetuation of, revolution.

To the extent that 'the Proletkult organized literary studios to provide working-class readers with an elementary literary education' (SovLit), it can be argued that its aim was to provide the ability for the proletariat to devise and develop the mechanisms through which it represented both society and itself and, therefore, that it created the conditions whereby the proletariat was able to develop an art form which was able to perpetuate the proletarian revolution.

However, it is also interesting to reflect on the extent to which the desire of the Proletkult for autonomy from the formal state apparatus, and the resistance this met from the People's Commissariat for Enlightenment, eventually defined how far the goals of any new proletarian culture, as enacted, came to be internally or externally generated. This is to ask whether the state changed to suit the proletariat or the proletariat was changed to suit the state.

\section{Adaptive Systems}

'The purpose of a system is what it does ... And what the viable system does is to survive' (Beer). ${ }^{3}$

Writing earlier, in the cybernetics literature, the psychiatrist W. Ross Ashby, quoting E. H. Starling, has this to say: 'Organism and environment form a whole and must be viewed as such' (Ashby 1960: 8). ${ }^{4}$ It is clear from this that Ashby is thinking of much the same structure as Bogdanov. The notion of organism in the environment that Ashby introduces - one where 'the organism affects the environment, and the environment affects the organism ...' (Ashby 1960: 37) - is again a reflection of Bogdanov's bi-regulator.

The theme of'system-in-environment' is fundamental to adaptive theory and consistent with both Bogdanov's bi-regulator and the Marxian notion that man and society co-create each other.

3 The term 'viable system', which is implicit in the works by Beer cited in the references, was often used by him in public addresses but is not found in his published works.

4 Note that Ashby, who includes Starling in the index to Design for a Brain, does not give a bibliographic reference. 


\section{Ashby's Ultrastable System}

Many of the adaptive models are informed by a general area of study called cybernetics, some form or other of which always lies at the core of adaptive theory. The word itself is a development of the Greek word kybernetes meaning, roughly, steersmanship, and was used by Plato in the Republic ${ }^{5}$ around 370 $\mathrm{BC}$ to compare the activities of social governance or statesmanship with those of a person steering a boat across open water, needing to make small corrective adjustments to take account of the ebb and flow of the tides and currents in order to achieve the goal of arriving safely into port. The Latin equivalent of kybernetes is gubernator - the root of the English word 'governor' which reveals its mixed origins by referring to both 'a ruler' and that part of a self-regulating device that does the regulating, for example the thermostat on a central heating or air-conditioning device.

Ashby's work in cybernetics led to the definition of the 'Law of Requisite Variety' (Ashby 1964) and the 'ultrastable system' (Ashby 1960). Ashby's research into the construction of learning machines using cybernetic principles led to the insight that the basic model needed to be extended to include a second feedback loop - one that assessed not the success or failure of a particular activity but the impact of that activity, or, more correctly, the impact of the environmental response to that activity, on the acting system or organization. With the introduction of the ultrastable system, Ashby makes it explicit that action cannot exist in a vacuum; rather, in a sentient or perceiving system, it exists in the context of the benefit of the system as a whole.

Where Ashby's model identifies the need for a systemic or organizational context to be present in order for learning to occur, Beer's Viable System Model (VSM) extends the notion of the 'reacting system' (Beer 1985). His extension takes it from being a simple or single homogeneous activity and defines the conditions necessary to manage a complex of potentially heterogeneous activities which, collectively and individually, contribute to the creation of the systemic whole. Beer also extends the ability for organizational learning and/or adaptation by introducing the concept of'recursion'(structural similarity between levels of organizational complexity) which allows for some degree of autonomy in the making of local adaptive change so long as it does not compromise the integrity of the whole.

\section{Beer's Viable System Model}

What is clear when comparing the models is that they share two common threads. The first is structural, in that Ashby's 'essential variables', 'second feedback loop' and 'reacting system' parallel Beer's 'systems 5, 4, and 3'; $;$ the second is the function of their proxies for organizational identity (i.e., the 'essential variables' and 'system 5'). In both cases, these function as external (and therefore unchangeable) arbiters of rightness. Identity (and, therefore, rightness) is fixed for the lifetime of the system or organization. Whilst this may hold in mechanical or individual biological systems, it is clearly not the case at the level of (biological) population evolution or at those of psychological, social or cultural change where'what-good-looks-like'is dynamic, the result of learning, experience and changing desire.

\section{The Trialogue}

The trialogue, developed by Dudley $(2000,2007)$ as an extension of Ashby's and Beer's models, overcomes this problem by rendering organizational identity 'plastic' - an emergent and dynamic entity existing at the intersection of environmental and structural possibility. There is an obvious (if latent) problem with this: in the absence of an established moral or strategic compass, there is the possibility that the organization becomes capricious, wantonly opportunistic or possibly catatonic. However, when it is accepted that the trialogue operates as the management element of a viable system and

5 See the translation of Waterfield 1994

6 This is figuratively, rather than strictly, correct because of the additional complexity introduced in the VSM which requires the formal separation of 'system 3' as a unifying management function. Because it utilizes only a single 'reacting system', this is not necessary in Ashby's model. 
is therefore subject to the embeddedness implied by Beer's notion of recursion, it becomes apparent that there will be both ethico-moral and performativity imperatives (as an accepted function of membership) which will tend to hold local behaviours away from (being accepted as) dysfunctional extremes.

Understood in this way, the trialogue can be said to provide a basis for understanding the changes that take place (in systemic identity) along a psycho-social continuum running from self-directed or experiential learning through formal education and/or socialization on to the more directive forms of psychotherapy. All of this can be seen as responses to, or manipulation of, environmental and/or internal factors in such a manner as to render currently held notions of identity problematic, thereby instigating, and then supporting, adaptive or desirable change.

\section{Embedding the Trialogue in the VSM}

It is possible to place Bogdanov's notions within this trialogue structure:

Any adaptive system conceived in the trialogue way is necessarily in a bi-regulative relationship with its environment. At the lower level of the model, the individual activities that the system or complex undertakes are activities that impact on the environment and respond to environmental reactions, by which local performance is assessed; and the impact of wider environmental response on the system as a whole affects the (systemic internal) construction of the context in which those activities are undertaken at the higher (or meta-systemic) level of the model. Podbor can be viewed as the process of the operational level of the system or complex within the context of the values established at the meta-level; and crisis can be viewed as the name Bogdanov gives to a change of identity, that is, a radical redefinition of the system or complex by virtue of a radical redefinition of the context in which the system or complex has meaning as a system or complex. And which, in parallel with the mechanisms of bi-regulation and podbor, therefore initiates a new trajectory of systemic development.

\section{Reflections (I)}

'The proletariat must have its own class art to organize its own forces in social labor, struggle, and construction' (Roberts 1998: 16).

That the Proletkult was conceived as a movement for consolidating revolutionary momentum following the revolution proper (in counter-position to Boal's'rehearsal for revolution') seems beyond doubt, as is the general conclusion that culture in general, and cultural products in particular, can be used as political 'weapons'.

In the light of the discussion above, it is also clear that it would have been possible for Bogdanov to have conceptualized the revolution as a societal-level crisis - as the radical redefinition of the relationship between the ruling class and the masses and the re-establishment of a new relationship between the proletariat and the Bolshevik leadership; and, as a result of this, the establishment of a new developmental trajectory for society as a movement of progressive podbor, controlled by virtue of tektological understanding.

Proletarian culture then becomes a method for ensuring that, as this societal podbor progresses, it continues along a path that cements the social gains made possible by the revolution. Here again, as with Boal, culture is acting to mediate between those who make up society and the society which they create. Indeed, the extent to which 'the Proletkult organized literary studios to provide working-class readers with an elementary literary education' (SovLit) suggests a commitment (of the kind outlined by Boal) to providing the ability to create cultural products to those who are directly affected by the society that such products will help to create. 
When an analysis is undertaken using adaptive systems theory, however, a number of points arise.

At the most obvious level, it is possible to envisage a (politico-economic model of) society as a high-level system with the system of production and the system of labour as two interacting (i.e., bi-regulating) sub-systems operating according to the rules that set the context for performance, or interaction, as being determined by the higher level. Culture, according to both Bogdanov and Boal, functions in order to refresh, or recreate, society in a manner that ensures that the dominant class remains dominant (e.g., Aristotle's conception of 'coercive tragedy').

Revolution, as the radical redefinition of the identity of the higher-level system, changes the context of the interaction of the sub-systems and, thereby, redefines the basis of their bi-regulation. This in turn creates the potential for a new developmental trajectory of progressive podbor. At this point, culture, as a political weapon, becomes key.

Adaptive systems have a somewhat counter-intuitive capability - because, as per Ashby's 'second feedback loop', the relationship between the system and its environment is, actually, between its identity and the environment, the system can change in order to stay the same - that is that, when an adaptive system is presented with a challenge from the environment, it will alter itself and/or its behaviour in such a way as to maintain the relationship between its identity and the currently prevalent environmental conditions. Culture, and individual cultural products viewed as adaptive systems, can reinforce the conservative tendency, create the conditions for the ongoing problematization of it, or create the conditions for forming a new orthodoxy.

\section{Reflections (II)}

In previous sections, culture was viewed as the lens through which the individual viewed society, and the mirror through which individuals saw themselves reflected as members of that society, but that culture does not exist in a vacuum; it is always historically, ideologically and theoretically determined. That is, any form of didactic cultural product is motivated by the beliefs of its producer.

This tends to suggest that, following the revolution - and the radical redefinition of the identity of the politico-economic system - the bi-regulating elements of the means of production and of labour were not miraculously made free (from bourgeois domination) and equal (in terms of perceived productive value) to define their own new world but were immediately re-constrained in a different (if opposite) wider system, one that also externally determined the nature of the legitimacy of their bi-regulating interactions, and therefore also determined what would be acceptable as legitimate cultural forms or products.

When it comes to cultural critique, or the attempt to use cultural products to bring about directed social change, it seems that emancipatory culture, including its cultural products and forms, is legitimately able only to provide the means for forming the questions that problematize the current status quo, and therefore create the conditions that might lead to or perpetuate - but not create - social change. There is a very fine line between didactic liberation and propaganda.

It could be argued that Bogdanov, in attempting to hand control of the production of cultural forms directly to the proletariat, was attempting to avoid this retaking of control; and that the resistance to the attempts of the Proletkult to maintain autonomy from the central apparatus was symptomatic of the existence and operation of such a wider system. 


\section{Conclusion}

The aim of this paper was to consider the extent to which Bogdanov's notion of 'podbor', as interpreted by Poustilnik as 'assemblage' or, possibly, construction which appears more aligned with the original definition of tektology, was sufficient to allow an interpretation of tektological complexes as adaptive systems (as they would be understood in modern English). And, from that, the extent to which this would allow the intellectual basis for consideration of the Proletkult idea as the attempt to create an environment that would encourage and ensure the continued development of the (Bolshevik version of the) Russian revolution.

Using Boal's 'theatre of the oppressed' as an example, the exploration moved to consider the utility of cultural products as political weapons that might be used to ensure that the voice of the revolution would be retained by the proletariat (in this case, Boal's 'oppressed'). Applying adaptive theory to this suggested that there were, of necessity, contradictions that tended to arise from the presence of a 'revolutionary vanguard' that could (in the absence of active measures to prevent it) retain power following any form of emancipatory revolution and thus, at worst, simply replace one form of oppression with another - a situation which both Bogdanov and Boal made efforts to overcome. To this extent, the consideration herein achieved its purpose.

More broadly, it is apparent that cultural products are not neutral but directed, a function of their producers, and, as such, have, alongside the potential for good - as in the case of the psychology of Bateson and Bowlby and the social engineering implicit in the third order cybernetics of Lepskiy - the ability to do harm. The weaponization of such products (i.e., the conscious use of them to do harm from low-level 'trolling' to 'information-psychological' warfare) is likely to be one of the major social challenges of the coming decades. And the democratization of the ability to produce cultural artefacts, especially the ability for them to be disseminated (instantly and broadly) using modern communications technologies, serves only to extend their reach.

\section{Commentary by Orsan Senalp}

In this piece, Peter Dudley offers an account of Bogdanov's vision of culture and Proletkult. Dudley is the editor of the 1996 translation of the first part of Bogdanov's Tektology - Universal Science of Organisation. As an expert on both Bogdanov's Tektology and the later development of systems science or systems thinking, he invites us to see Proletkult as a conscious tektological design, or, with the modern systems language, as a complex adaptive system. Referring to Simona Poustulnik's earlier work, Dudley reminds us that the Russian term Bogdanov used (podbor instead of otbor) when talking about the nature of the interactions among elements of any system is critical. It allows one to visualize the dynamic and ever-changing assemblage of agents and their relationships in any social network; how the elements that are forming the culture of any social group, class, and human society interact dynamically with each other within the wider global context; how changes occur and spread from molecular to systemic level by penetrating and altering the elements forming environments at each scale. So it becomes possible to grasp the nature of and the regularities in complex interactions and changes taking place from sub-atomic to atomic and molecular levels, to ideas, norms and institutions. The way the ideological, cultural and political spheres are connected to the natural one (the so-called dialectical relations between the sub- and the super-structure) opens up before our eyes and becomes concrete. Indeed, Bogdanov asserted in his short autobiography that Tektology and Proletkult - foreseen in his original plan as Union for Proletarian Culture - were his two main contributions. It makes 
Dudley's claim highly plausible. Since tektology was a universal science of organization, and culture, like everything else, can be seen and studied as an organization, then tektology can also be applied to culture to reorganize it. Tektology and Proletkult were parallel and interconnected projects, thought of as the main tools of workers' cultural revolution. Tektology, in this sense, was the highest form of cultural production; to be learned, used, developed, and spread by the workers themselves. A science that can transform and reorganize scattered and artificially divided bourgeois cultural forms including specialized bourgeois sciences. The task was achievable only from the workers' perspective - for and by the workers. Proletkult was an organized complex that was organized by workers and in which the workers organized the production of their own culture. It was meant to spread such culture, through interactions with the wider environment, which was the capitalist world system. And the aim was the co-evolution of the collectivist order in and outside the Proletkult. This perspective indeed suggests that the contemporary cultural-creative worker, the so-called intellectual- or cyber-proletariat, might fit the role of the protagonist of radical change better than the industrial worker.

\section{References}

Ashby, WR. 1960. Design for a Brain. London: Chapman and Hall.

Ashby, WR. 1964. An Introduction to Cybernetics. London: Methuen.

Bateson, G. 1972. Steps to an Ecology of Mind, London: University of Chicago Press.

Beer, S. 1979. The Heart of Enterprise. Chichester: Wiley.

Beer, S. 1981. The Brain of the Firm. Chichester: Wiley.

Beer, S. 1985. Diagnosing the System for Organizations. Chichester: Wiley.

Boal, A. 1979 (2nd ed. 2000). Theatre of the Oppressed. London: Pluto Press.

Bogdanov, AA. 1989. Tektologiya: Vseobshaya Organizatsionaya Nauka Books 1-3 Moscow: Ekonomika.

Bogdanov, AA. 1996. Bogdanov's Tektology Book 1 (Editor: P. Dudley). Hull: Centre for Systems Studies Press.

Bowlby, J. (1969-1980), Attachment and Loss (vols. 1-3), London: Pimlico.

Dudley, P. 2000. Management Quality or Quality Management? Doctoral Dissertation. University of Hull.

Dudley, P. and Young, M. 2007. Leadership and Cybernetics. Oxford: Oxford Saïd Business School.

Hauser, A. 1957. The Social History of Art (Translation: F.P.B. Godman). New York: Vintage Books.

Lepskiy, V. 2019. Self Developing Poly-Subject Environments in Improving Control Processes Involving Society, IFAC Papers Online, 55-25 (2019) 337-342: www.sciencedirect.com. Accessed May 2021.

Maturana, H. and Varela, F. 1980. Autopoiesis and Cognition: The Realization of the Living. Dordrecht: D. Reidel.

Neumann, J. von. 1966. Theory of Self-Reproducing Automata. Urbana; London: University of Illinois Press.

Poustilnik, SN. 1995. "Assemblage as the Basis of Bogdanov's Tektology", Voprosy filosofii. 8 (in Russian).

Poustilnik, SN. 1998. "Biological Ideas in Tektology." In Alexander Bogdanov and the Origins of Systems Thinking in Russia. Edited by J.Biggart, P.Dudley, and F.King. Aldershot: Ashgate.

Roberts, J. 1998. The Art of Interruption. Manchester: Manchester University Press. 
Waterfield, R. (Translator) 1994. Plato. Republic. Oxford: Oxford University Press.

SovLit: http://www.sovlit.net/bios/proletkult.html. accessed 07/05/2014.

\section{Authors information}

Peter Dudley is a freelance academic and management consultant. He holds a PhD in Management Systems and Sciences (cybernetics) from the University of Hull, and is a visiting fellow of the University of Manchester Business School (MBS) and an associate of the York Centre for Complex Systems Analysis (YCCSA). Peter was the editor and team leader of the group that brought the first complete translation of Bogdanov's Tektology, Book 1, into English, as part of his collaboration with the Russian Academy of Sciences Institute for Systems Analysis, and continues to integrate ideas from the Tektology into his current work.

Orsan Senalp is a researcher with a background and expertise in trade union, labour and social justice movements and the global political economy. He is currently researching at the University of Hull, Centre for Systems Studies. His research topic is the work and ideas of Aleksandr Bogdanov and their relevance to the systems paradigm and the unity of science question. 